CARDIOVASCULAR MEDICINE

\title{
Catheter based intracoronary brachytherapy leads to increased platelet activation
}

\author{
M Jaster, V Fuster, P Rosenthal, M Pauschinger, Q-V Tran, D Janssen, W Hinkelbein, \\ P Schwimmbeck, H-P Schultheiss, U Rauch
}

Heart 2004;90:160-164. doi: 10.1136/hrt.2003.013482

See end of article for authors' affiliations

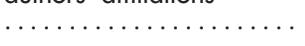

Correspondence to: Dr Ursula Rauch,

Department of Cardiology, University Hospital Benjamin Franklin, Free University of Berlin Hindenburgdamm 30 , 12200 Berlin, Germany; ursula.rauch@medizin. fu-berlin.de

Accepted 4 July 2003
Background: Vascular brachytherapy (VBT) after percutaneous coronary intervention (PCI) is associated with a higher risk of stent thrombosis than conventional treatment.

Objective: To investigate in vivo periprocedural platelet activation with and without VBT, and to assess a possible direct effect of radiation on platelet activation.

Design: Of 50 patients with stable angina, 23 received VBT after $\mathrm{PCl}$, while 27 had $\mathrm{PCl}$ only. The 23 patients who received VBT after $\mathrm{PCl}$ were pretreated for one month with aspirin and clopidogrel. Platelet activation was assessed by flow cytometry.

Results: The two patient groups did not differ in their platelet activation before the intervention. There was a significant increase in activation immediately after VBT, with $21.2 \%$ (interquartile range $13.0 \%$ to $37.6 \%$ ) thrombospondin positive and $54.0 \%(42.3 \%$ to $63.6 \%)$ CD 63 positive platelets compared with $12.7 \%$ (9.8\% to $14.9 \%$ ) thrombospondin positive and $37.9 \%(33.2 \%$ to $45.2 \%)$ CD 63 positive platelets before the intervention ( $p<0.001$ and $p<0.01$, respectively). Patients without VBT had no periprocedural difference in platelet activation immediately affer $\mathrm{PCl}$. No increase in platelet activation was found affer ex vivo irradiation of blood samples obtained from healthy controls.

Conclusions: Catheter based intracoronary VBT carried out according to current standards is highly thrombogenic. The current antithrombotic treatment with aspirin and clopidogrel is not sufficient to suppress platelet activation during the procedure. From in vitro experiments, it appears that platelet activation during brachytherapy is not caused by irradiation but by the procedure of catheter based VBT.
$\mathrm{P}$ ercutaneous coronary interventions (PCI) now include more than one million stent implantations worldwide each year. Stent implantation has been shown to reduce the risk of restenosis ${ }^{1-3}$ by eliminating vascular contraction. ${ }^{45}$ However, stents do not inhibit neointimal proliferation but tend to induce it more than other devices. ${ }^{67}$ In-stent restenosis is a major limitation of intracoronary stent implantation and affects approximately 300000 patients worldwide each year. The rate of restenosis caused by neointimal proliferation $^{89}$ is still high, ranging from 15$50 \%$ depending on the type of lesion treated..$^{1-3}$ There is a higher incidence of recurrent restenosis after PCI for in-stent restenosis. ${ }^{10}$

A new treatment strategy using ionising radiation for preventing recurrent in-stent restenosis after PCI is catheter based intracoronary $\beta$ radiation (vascular brachytherapy, VBT). ${ }^{11-13}$ In large clinical trials, both $\beta$ and $\gamma$ radiation have proven effective in reducing restenosis. ${ }^{14-16}$ This new treatment is followed by an increased number of adverse events such as subacute and late thrombosis, ${ }^{16-19}$ but the mechanism of the increase in thrombotic events after VBT is not yet well understood. Platelet activation has been identified as an independent risk factor for acute and subacute ischaemic events after PCI. ${ }^{20}$ These thrombotic occlusions are associated with increased mortality. ${ }^{21}{ }^{22}$ The increased incidence of subacute and late adverse events after brachytherapy reflects its high thrombogenicity, which cannot be completely suppressed by current antiplatelet drugs, especially after new stent placement. ${ }^{19} 23$

Our study aimed to investigate whether brachytherapy with $\beta$ radiation emitted by ${ }^{90} \mathrm{SR} /{ }^{90} \mathrm{Y}$ source trains leads to higher platelet activation than PCI without radiation. We also carried out in vitro experiments on whole blood, applying high and low dose radiation to assess a possible direct effect of irradiation on platelet activation and blood thrombogenicity.

\section{METHODS \\ Patients}

The study included 50 patients with stable angina, 23 of whom (mean (SD) age, 61 (9) years; 19 men, four women) were treated with the Novoste Beta-Cath system for in-stent restenosis after successful primary intervention. Twenty seven patients (58 (9) years; 23 men, four women) who underwent PCI without irradiation served as controls. Brachytherapy and control patients did not differ significantly in age, sex, distribution of coronary risk factors, or number of diseased vessels (table 1). Non-ionic contrast medium was used in all patients (Ultravis 370, Schering, Berlin, Germany). The left circumflex artery was treated more often in controls.

The radioactive source used was ${ }^{90} \mathrm{Sr} /{ }^{90} \mathrm{Y}$, a $\beta$ emitter with a maximum energy of $2.27 \mathrm{MeV}$. All irradiated patients were treated with the same source trains between March and October 2000 after informed written consent and approval by the local ethics committee. Radiation doses were 18.4, 23.0, or $25.3 \mathrm{~Gy}$, depending on the major vessel diameter accessed by intravascular ultrasound (IVUS) (table 2). We used two different source trains: one device $40 \mathrm{~mm}$ long with 16 active encapsulated seeds and the other $60 \mathrm{~mm}$ long with 24 seeds.

\footnotetext{
Abbreviations: FITC, fluorescein isothiocyanate; IVUS, intravascular ultrasound; PCl, percutaneous coronary intervention; TSP, thrombospondin; VBT, vascular brachytherapy
} 
Table 1 Clinical details of the patients and controls

\begin{tabular}{lll}
\hline & $\begin{array}{l}\text { Patients treated with } \\
\text { brachytherapy }(\mathbf{n}=\mathbf{2 3})\end{array}$ & $\begin{array}{l}\text { Patients treated without irradiation } \\
(\mathbf{n}=\mathbf{2 7})\end{array}$ \\
\hline Age (years) & $61(9)$ & $58(9)$ \\
Sex (F/M) & $4 / 19$ & $4 / 23$ \\
Treated coronary artery & $12 / 23$ & $11 / 27$ \\
LAD & $1 / 23$ & $9 / 27$ \\
LCx & $10 / 23$ & $7 / 27$ \\
RCA & $1.9(0.8)$ & $2.2(0.7)$ \\
Number of diseased arteries & $14 / 23$ & $16 / 27$ \\
Smoking & $5 / 23$ & $7 / 27$ \\
Diabetes & $12 / 23$ & $13 / 27$ \\
Hypertension & $20 / 23$ & $22 / 27$ \\
Lipids & $1 / 23$ & $2 / 27$ \\
Family history & $359(64)$ & $342(67)$ \\
ACT of the procedure (s) & \\
\hline Values are mean (SD) or $\mathrm{n}$. & & \\
* $\mathrm{p}<0.05$. & \\
ACT, activated clotting time; LAD, left anterior descending coronary artery; $L C x$, left circumflex artery; RCA, right \\
coronary artery.
\end{tabular}

Table 2 Comparison of the different source trains used in our study between March and September 2000

\begin{tabular}{lll}
\hline & $\begin{array}{l}40 \mathrm{~mm} \text { source } \\
\text { train }\end{array}$ & $\begin{array}{l}60 \mathrm{~mm} \text { source } \\
\text { train }\end{array}$ \\
\hline $\begin{array}{lll}\text { Patients treated with different } \\
\text { train doses }(\mathrm{n})\end{array}$ & \\
$18.4 \mathrm{~Gy}$ & $19 / 23$ & $4 / 23$ \\
$23.0 \mathrm{~Gy}$ & $7 / 19$ & $0 / 4$ \\
$25.3 \mathrm{~Gy}$ & $6 / 19$ & $2 / 4$ \\
\hline
\end{tabular}

The dose rate varies for each source train and depends on the time of radioactivity storage.

The dose rate at the target point $2 \mathrm{~mm}$ away from the centre of the source train was determined to be $0.1 \mathrm{VGy} / \mathrm{s}$ for the $40 \mathrm{~mm}$ source train and $0.08 \mathrm{~Gy} / \mathrm{s}$ for the $60 \mathrm{~mm}$ source train, with a longer radiation time to achieve an equal dose. No new stent placement was undertaken during brachytherapy.

All patients treated with brachytherapy received dual antiplatelet treatment with aspirin and an ADP receptor antagonist (clopidogrel $300 \mathrm{mg}$ loading dose followed by $75 \mathrm{mg}$ per day) three to four weeks before and at least six months after elective irradiation. No pretreatment was given in the control group. Control patients were treated with aspirin and additionally received an ADP receptor antagonist for two weeks after the intervention only in cases of stent implantation (12/27) or stent angioplasty (5/27). No glycoprotein IIb/IIIa receptor antagonist was used in any of the cases.

Blood samples were taken before and immediately after the intervention in the catheter laboratory, during effective heparinisation and before the removal of the venous sheath in all patients. The blood was analysed immediately. Blood samples after 24 hours were taken the next morning before breakfast.

\section{IVUS}

Intravenous heparin was given to obtain a target activated clotting time (ACT) of 300 seconds. Intravascular ultrasound (Endosonics) was carried out in irradiated patients to confirm a significant in-stent restenosis-that is, more than $50 \%$ cross sectional area. Stent malposition or underexpansion was excluded as the cause of the angiographically visualised in-stent restenosis. A motorised pull back procedure was applied at $1 \mathrm{~mm} / \mathrm{s}$. After balloon angioplasty, IVUS was done to confirm a residual stenosis with a lumen diameter of less than $30 \%$. The elastica externa was assessed as the vessel diameter containing the target cells for irradiation.

\section{Platelet activation measurement}

Whole blood was collected in a special sample medium (containing EDTA, hydroxychloroquine sulfate, sodium hydroxide, and heparin sodium) through a $1 \mathrm{~mm}$ Wassermann cannula without a tourniquet and immediately fixed in paraformaldehyde $(1 \%)$. Platelet activation was determined by flow cytometry as described. ${ }^{17}$ In short, platelet-rich plasma was obtained by centrifugation at $100 \mathrm{~g}$ for 10 minutes (room temperature). Platelets were counted and diluted with phosphate buffered saline to a final concentration of 1000/nl. Aliquots were incubated with saturated concentrations of monoclonal antibodies against the activation dependent activation markers CD 63 and thrombospondin and the constitutively expressed glycoprotein IIb/IIIa. A second FITC labelled anti-mouse antibody was added to detect the primary antibodies. Flow cytometry was then carried out, with 10000 events acquired for each sample. Data are given as the percentage of marker positive platelets for thrombospondin and $\mathrm{CD} 63$ or as the mean immunofluorescence intensity for glycoprotein IIb/IIIa.

\section{Ex vivo radiation experiments}

Blood samples were obtained from healthy subjects without a tourniquet and immediately mixed with citrate. Whole blood was divided into aliquots, one serving as a control and the others being irradiated. Two different doses (20 Gy and $160 \mathrm{~Gy}$ ) were used in repeated experiments to cover the dose range applied to blood in patients undergoing brachytherapy. A linear accelerator with a 6 or $18 \mathrm{MeV}$ photon beam served as the radiation source. Immediately after irradiation, which took about 15 minutes, all aliquots were fixed in $1 \%$ paraformaldehyde and analysed by flow cytometry as above.

\section{Statistics}

If data were normally distributed, Student's $t$ test was used to compare continuous variables. Results are expressed as mean (SD). If data were not normally distributed, we used Wilcoxon's rank test to compare continuous variables. Results are expressed as medians and interquartile ranges. Binary variables were compared using the $\chi^{2}$ test or Fisher's exact test when appropriate. The Mann-Whitney U test was chosen to compare different groups. A probability value of $\mathrm{p}<0.05$ in the two sided test was considered significant. 
Table 3 Platelet activation in patients treated with and without vascular brachytherapy

\begin{tabular}{|c|c|c|}
\hline & $\begin{array}{l}\text { Treated with VBT } \\
(\mathrm{n}=23)\end{array}$ & $\begin{array}{l}\text { Controls } \\
(n=27)\end{array}$ \\
\hline $\begin{array}{l}\text { \% TSP positive platelets } \\
\text { in blood before the } \\
\text { intervention }\end{array}$ & $\begin{array}{l}12.7 \\
(9.8 \text { to } 14.9)\end{array}$ & $\begin{array}{l}10.9 \\
(8.8 \text { to } 14.1)\end{array}$ \\
\hline $\begin{array}{l}\text { \% TSP positive platelets } \\
\text { in blood after the } \\
\text { intervention }\end{array}$ & $\begin{array}{l}21.2 \\
(13.0 \text { to } 37.6) \dagger \ddagger\end{array}$ & $\begin{array}{l}9.2 \\
(7.4 \text { to } 10.1)\end{array}$ \\
\hline $\begin{array}{l}\% \text { CD } 63 \text { positive } \\
\text { platelets in blood before } \\
\text { the intervention }\end{array}$ & $\begin{array}{l}37.9 \\
(33.2 \text { to } 45.2)\end{array}$ & $\begin{array}{l}46.3 \\
(33.7 \text { to } 51.3)\end{array}$ \\
\hline $\begin{array}{l}\% \text { CD } 63 \text { positive } \\
\text { platelets in blood after } \\
\text { the intervention }\end{array}$ & $\begin{array}{l}54.0 \\
(42.3 \text { to } 63.6)^{*} \ddagger\end{array}$ & $\begin{array}{l}41.2 \\
(34.1 \text { to } 49.8)\end{array}$ \\
\hline $\begin{array}{l}\text { GP Illb/Illa on platelet } \\
\text { surface before the } \\
\text { intervention }\end{array}$ & $\begin{array}{l}305.7 \\
(269.5 \text { to } 381.2)\end{array}$ & $\begin{array}{l}309.3 \\
(276.9 \text { to } 365.4)\end{array}$ \\
\hline $\begin{array}{l}\text { GP Ilb/Illa on platelet } \\
\text { surface after the } \\
\text { intervention }\end{array}$ & $\begin{array}{l}299.7 \\
(263.1 \text { to } 377.4)\end{array}$ & $\begin{array}{l}301.0 \\
(261.7 \text { to } 384.7)\end{array}$ \\
\hline
\end{tabular}

Platelet activation is indicated by the median and interquartile range of TSP positive and CD 63 positive platelets before and after the intervention.

${ }^{*} p<0.01$ between patient groups (Mann-Whitney $U$ test); $\uparrow p<0.001$ between patient groups; $\neq \mathrm{p}<0.01$ pre $v$ post intervention in patients treated with VBT (Wilcoxon's rank test); glycoprotein Ilb/Illa remained unchanged (NS).

GP, glycoprotein; TSP, thrombospondin; VBT, vascular brachytherapy.

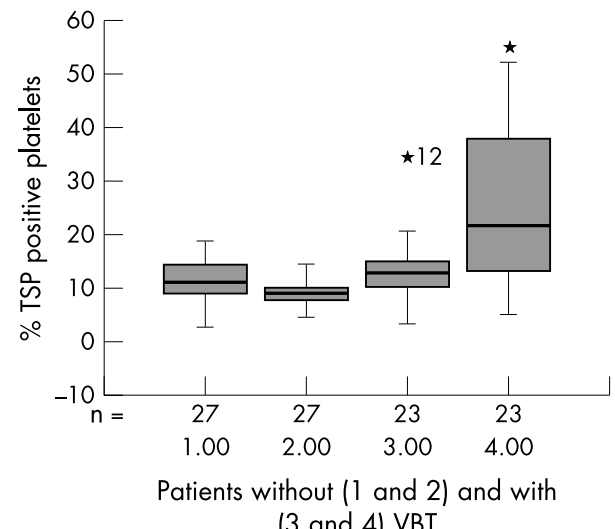

(3 and 4) VBT

Figure 1 Percentages of thrombospondin (TSP) positive platelets are given as the median and interquartile range. Patients with vascular brachytherapy (VBT) are indicated by number 3 (before the intervention) and 4 (after the intervention). TSP positive platelets increased significantly after VBT ( $\left.{ }^{*} p<0.01\right)$. Patients without VBT remained the same before (number 1) and after the intervention (number 2).

Comparing the number of TSP positive platelets after the intervention in patients without (number 2) and with VBT (number 4) showed significantly increased platelet activation in the irradiation group.

\section{RESULTS}

The two patient groups were comparable in their clinical data (table 1). Table 2 shows the number of patients treated with different source trains. Before the intervention, the two patient groups did not differ significantly with respect to the in vivo activation of circulating platelets (table 3). There was a significant increase in thrombospondin positive platelets immediately after PCI with brachytherapy compared with the percentage found before the intervention $(p<0.01)$ or after PCI without irradiation $(\mathrm{p}<0.001)$ (fig lA). CD 63 positive platelets also increased in VBT treated patients immediately after the intervention compared with the CD 63 before the intervention $(p<0.01)$ or after PCI without irradiation $(\mathrm{p}<0.01)$ (table 3). These data indicate that catheter based intracoronary brachytherapy is associated with increased in vivo platelet reactivity. Glycoprotein IIb/IIIa on the platelet surface remained unchanged and was comparable in the two patient groups. There was no heterogeneity in the actual sampling time between the groups.

IVUS was used before and after intervention in the VBT group. IVUS itself may cause plaque perturbation in the coronary artery, leading to increased platelet reactivity. To rule this out as a possible effect, platelet activation was assessed in a small control group $(n=6)$, in which IVUS was done before and after stent implantation. The percentage of TSP and CD 63 positive platelets was not altered during intervention (TSP: $10.9 \%$ (interquartile range $8.3 \%$ to $18.2 \%$ ) before $v 12.0 \%(9.4 \%$ to $14.5 \%)$ immediately after intervention, $\mathrm{p}=0.917$; for CD 63: $32.4 \%$ (30.6\% to $46.0 \%)$ before $v$ $36.2 \%(33.7 \%$ to $42.4 \%)$ immediately after intervention, $\mathrm{p}=0.753)$.

\section{In vitro experiments}

Irradiation of blood samples (not platelet-rich plasma) with target doses used in humans did not affect platelet activation. Even eight times higher doses did not increase platelet activation compared with the non-irradiated control aliquots (table 4). This indicates that platelet activation is not directly affected by irradiation.

\section{DISCUSSION}

This study is the first to show that platelet activation is increased by the brachytherapy currently applied in clinical practice. A notable increase was found after brachytherapy compared with PCI without irradiation. We have previously identified increased platelet activation after conventional PCI as an independent risk factor for acute ischaemic events. ${ }^{20}$ The data on radiation delivery devices submitted for US Food and Drug Administration (FDA) approval showed that patients treated with radiation benefit from a reduction in recurrent stenosis but also have the disadvantage of an increased rate of thrombotic events. ${ }^{192} 24$ Thrombotic occlusions are associated with increased mortality after $\mathrm{PCI}^{21}$ and an increased risk of myocardial infarctions after

Table 4 Ex vivo experiments to assess irradiation dependent platelet activation

\begin{tabular}{|c|c|c|c|}
\hline & $\begin{array}{l}\text { After } 20 \text { Gy irradiation } \\
(n=4)\end{array}$ & $\begin{array}{l}\text { After } 160 \text { Gy irradiation } \\
(n=4)\end{array}$ & $\begin{array}{l}\text { Not radiated control samples } \\
(n=8)\end{array}$ \\
\hline $\begin{array}{l}\text { \% TSP positive } \\
\text { platelets }\end{array}$ & 10.8 (9.9 to 12.7$)$ & 11.0 (10.5 to 13.2$)$ & 13.7 (10.8 to 16.3$)$ \\
\hline $\begin{array}{l}\% \text { CD } 63 \text { positive } \\
\text { platelets }\end{array}$ & 18.1 (16.5 to 20.5 ) & 25.2 (21.9 to 35.0 ) & 23.4 (18.1 to 30.6$)$ \\
\hline $\begin{array}{l}\text { GPIlb/IIla on } \\
\text { platelet surface }\end{array}$ & 414.2 (379.4 to 466.6$)$ & 360.5 (318.2 to 407.6$)$ & 373.5 (336.8 to 412.3 ) \\
\hline \multicolumn{4}{|c|}{$\begin{array}{l}\text { Platelet activation tended to be higher in our in vitro experiments than in our patients. These differences may be due } \\
\text { to the irradiation procedure in our in vitro experiments, which took about } 15 \text { minutes. The blood of our study } \\
\text { patients, on the other hand, was fixed immediately after blood sampling to prevent any platelet activation. } \\
\text { GP, glycoprotein; TSP, thrombospondin. }\end{array}$} \\
\hline
\end{tabular}


VBT. ${ }^{14} 19232526$ The increase in platelet activation after brachytherapy is not suppressed by concomitant treatment with aspirin and clopidogrel. Both drugs were given to all 23 patients three to four weeks before elective brachytherapy. In the group of control patients, only those with PCI for in-stent restenosis or new stent implantation received ADP receptor antagonists in addition to aspirin. In these control patients, treatment with an ADP receptor antagonist started during the intervention. Control patients showed no change in platelet activation after the intervention. The results coincide with previous reports on periprocedural platelet activation in stable angina patients treated with PCI. ${ }^{27}$ The differences in medical treatment explain the tendency towards fewer CD 63 positive platelets before the intervention in patients who underwent VBT after taking antiplatelet treatment for three to four weeks. The lysosomal glycoprotein CD 63 is a marker for prolonged and severe platelet activation. Despite pretreatment with aspirin and clopidogrel for three to four weeks, platelet activation-as found for TSP and CD 63-increased during intracoronary brachytherapy. The more intense pretreatment with thienopyridines in the brachytherapy group makes the results even more striking.

Our results support the discussion of three different mechanisms for increased platelet reactivity after VBT: first, the irradiation itself affects in vivo platelet activation and blood thrombogenicity; second, the currently used catheter based radiation source trains and their time consuming procedures may be highly thrombogenic; and third, VBT affects platelet activation indirectly owing to endothelial damage. Nitric oxide/endothelium derived relaxing factor (NO/EDRF) produced by the intact endothelium inhibits platelet activation. This endothelium derived antithrombogenic effect may be reduced after VBT.

We undertook in vitro experiments to rule out a direct effect of irradiation on platelet activation. The doses used were biologically equivalent to those delivered by the radioactive sources. There was no direct radiation dependent effect on platelet activation in these in vitro experiments (table 4). The findings coincide with previous reports on short term irradiation in doses of up to $150 \mathrm{~Gy} .^{28}$ It remains to be shown whether the degree of platelet activation is determined by the procedure of catheter based intracoronary brachytherapy or by the effects of VBT on endothelial function. Platelet activation may be influenced by the length of the source train correlating with the endothelial damage and the indwelling time of the highly thrombogenic catheter based delivery system in the coronary artery. However, it can also be hypothesised that the negative impact of VBT on endothelial function may affect platelet reactivity after intracoronary brachytherapy.

Recent reports on VBT in patients receiving combined antiplatelet treatment (aspirin plus ADP receptor antagonist) showed an increased rate of subacute thrombosis after PCI with irradiation ${ }^{18}{ }^{19}$ compared with stenting without VBT. ${ }^{29} 30$ Our data showed that platelet activation after intracoronary brachytherapy was only incompletely suppressed by antiplatelet treatment with aspirin and clopidogrel. The second blood samples were taken immediately after the intervention during effective heparinisation. A possible effect of heparinisation on platelet activation cannot be excluded. However, all patients received heparin, so the groups remain comparable and the increase in platelet activation was found in the VBT group only.

Increased platelet reactivity after brachytherapy may trigger acute and subacute stent thrombosis after VBT and increase the number of myocardial infarcts, especially after new stent placement during VBT. ${ }^{19} 2326$ In an analysis of 473 patients with in-stent restenosis enrolled in various VBT protocols, subacute thrombosis occurred in three patients
$(0.9 \%)$ treated with VBT and in none of the placebo treated patients. ${ }^{19}$ The acute changes in platelet activation observed here cannot be related to alterations in platelet reactivity or thrombotic events found three to six months after VBT (late thrombosis). Factors to be considered in connection with late thrombosis are the damaged endothelium and thrombogenic vasculature at the site of injury where re-endothelialisation is delayed or fails to occur after irradiation. ${ }^{31} 32$

\section{Conclusions}

Platelet activation is increased after catheter based VBT compared with PCI without irradiation. This increase occurs despite aggressive antiplatelet treatment with aspirin and clopidogrel given for three to four weeks before brachytherapy. Our in vitro experiments did not show a direct effect of irradiation on platelets and indicated that catheter based VBT involving endothelial damage is a highly thrombogenic procedure.

\section{Authors' affiliations \\ M Jaster, M Pauschinger, Q-V Tran, D Janssen, P Schwimmbeck,} H-P Schultheiss, U Rauch, Department of Cardiology, University Hospital Benjamin Franklin, Free University of Berlin, Berlin, Germany

P Rosenthal, W Hinkelbein, Department of Radiooncology, University Hospital Benjamin Franklin

V Fuster, The Cardiovascular Institute, Mount Sinai School of Medicine, New York, USA

\section{REFERENCES}

1 Fischman DL, Leon MB, Baim DS, et al. A randomized comparison of coronary-stent placement and balloon angioplasty in the treatment of coronary artery disease. Stent Restenosis Study Investigators. N Engl J Med 1994;331:496-501.

2 Serruys PW, de Jaegere P, Kiemeneii F, et al. A comparison of balloonexpandable-stent implantation with balloon angioplasty in patients with coronary artery disease. Benestent Study Group. N Engl J Med 1994;331:489-95.

3 Serruys PW, van Hout B, Bonnier $\mathrm{H}$, et al. Randomised comparison of implantation of heparin-coated stents with balloon angioplasty in selected patients with coronary artery disease (Benestent II). Lancet 1998;352:673-81.

4 Mintz GS, Popma JJ, Hong MK, et al. Intravascular ultrasound to discern device-specific effects and mechanisms of restenosis. Am J Cardiol 1996:78:18-22.

5 Hoffmann R, Mintz GS, Dussaillant GR, et al. Patterns and mechanisms of instent restenosis. A serial intravascular ultrasound study. Circulation 1996;94:1247-54.

6 Kuntz RE, Gibson CM, Nobuyoshi M, et al. Generalized model of restenosis after conventional balloon angioplasty, stenting and directional atherectomy. J Am Coll Cardiol 1993;21:15-25.

7 Moreno PR, Palacios IF, Leon MN, et al. Histopathologic comparison of human coronary in-stent and post-balloon angioplasty restenotic tissue. Am J Cardiol 1999:84(A9):462-6.

8 Farb A, Sangiorgi G, Carter AJ, et al. Pathology of acute and chronic coronary stenting in humans. Circulation 1999;99:44-52.

9 Dussaillant GR, Mintz GS, Pichard AD, et al. Small stent size and intimal hyperplasia contribute to restenosis: a volumetric intravascular ultrasound analysis. J Am Coll Cardiol 1995;26:720-4.

10 Baim DS, Levine MJ, Leon MB, et al. Management of restenosis within the Palmaz-Schatz coronary stent (the US multicenter experience). The US Palmaz-Schatz stent investigators. Am J Cardiol 1993;71:364-6.

11 Wiedermann JG, Marboe C, Amols H, et al. Intracoronary irradiation markedly reduces restenosis after balloon angioplasty in a porcine model. J Am Coll Cardiol 1994;23:1491-8.

12 King SB, Williams DO, Chougule P, et al. Endovascular beta-radiation to reduce restenosis after coronary balloon angioplasty: results of the beta energy restenosis trial (BERT). Circulation 1998;97:2025-30.

13 Mazur W, Ali MN, Khan MM, et al. High dose rate intracoronary radiation for inhibition of neointimal formation in the stented and balloon-injured porcine models of restenosis: angiographic, morphometric, and histopathologic analyses. Int J Radiat Oncol Biol Phys 1996:36:777-88.

14 Teirstein PS, Massullo V, Jani S, et al. Catheter-based radiotherapy to inhibit restenosis after coronary stenting. N Engl J Med 1997;336:1697-703.

15 Waksman R, White RL, Chan RC, et al. Intracoronary gamma-radiation therapy after angioplasty inhibits recurrence in patients with in-stent restenosis. Circulation 2000;101:2165-71.

16 Leon MB, Teirstein PS, Moses JW, et al. Localized intracoronary gammaradiation therapy to inhibit the recurrence of restenosis after stenting. N Engl J Med 2001;344:250-6.

17 Verin V, Popowski Y, de Bruyne B, et al. Endoluminal beta-radiation therapy for the prevention of coronary restenosis after balloon angioplasty. The DoseFinding Study Group. N Engl J Med 2001;334:243-9. 
18 Costa MA Sabat M, van der Giessen WJ, et al. Late coronary occlusion after intracoronary brachytherapy. Circulation 1999;100:789-92.

19 Waksman R, Bhargava B, Mintz GS, et al. Late total occlusion after intracoronary brachytherapy for patients with in-stent restenosis. J Am Coll Cardiol 2000;36:65-8.

20 Tschoepe D, Schultheiss HP, Kolarov P, et al. Platelet membrane activation markers are predictive for increased risk of acute ischemic events after PTCA. Circulation 1993;88:37-42.

21 de Feyter PJ, de Jaegere PP, Serruys PW. Incidence, predictors, and management of acute coronary occlusion after coronary angioplasty. Am Heart J 1994; 127:643-51.

22 Rauch U, Osende J, Fuster $\mathrm{V}$, et al. Thrombus formation on atherosclerotic plaques: pathogenesis and clinical consequences. Ann Intern Med $2001 ; 134: 224-38$.

23 Leon MB, Teirstein PS, Moses JW, et al. Localized intracoronary gammaradiation therapy to inhibit the recurrence of restenosis after stenting. N Engl J Med 2001;344:250-6.

24 Sapirstein W, Zuckerman B, Dillard J. FDA approval of coronary-artery brachytherapy. N Engl J Med 2001;344:297-9.
25 Raizner AE, Oesterle SN, Waksman R, et al. Inhibition of restenosis with betaemitting radiotherapy: Report of the Proliferation Reduction with Vascular Energy Trial (PREVENT). Circulation 2000;102:951-8.

26 Sheppard R, Eisenberg MJ. Intracoronary radiotherapy for restenosis. N Engl J Med 2001;344:295-7.

27 Kolarov P, Tschoepe D, Nieuwenhuis HK, et al. PTCA: periprocedural platelet activation. Part II of the Duesseldorf PTCA platelet study (DPPS). Eur Heart J 1996;17:1216-22.

28 Weinmann M, Hoffmann W, Rodegerdts E, et al. Biological effects of ionizing radiation on human blood compounds ex vivo. J Cancer Res Clin Oncol 2000; 126:584-88

29 Colombo A, Hall P, Nakamura S, et al. Intracoronary stenting without anticoagulation accomplished with intravascular ultrasound guidance. Circulation 1995:91:1676-88.

30 Wilson SH, Rihal CS, Bell MR, et al. Timing of coronary stent thrombosis in patients treated with ticlopidine and aspirin. Am J Cardiol 1999;83:1006-11.

31 Hehrlein C, Stintz M, Kinscherf R, et al. Pure beta-particle-emitting stents inhibit neointima formation in rabbits. Circulation 1996;93:641-5.

32 Rauch U, Nemerson Y. Tissue factor, the blood, and the arterial wall. Trends Cardiovasc Med 2000; 10:139-43.

\section{IMAGES IN CARDIOLOGY}

\section{Ruptured plaque or embolised thrombus}

\section{A} 38 year old woman with acute chest pain was admitted to the hospital. Positive troponins and electrocardiographic signs of anterior wall myocardial infarction during atrial fibrillation were found. Echocardiography (panel below) showed hypokinesia of the anterior wall and severe mitral stenosis (arrowhead; LV, left ventricle; SC, spontaneous contrast). Coronary angiography showed an occlusion of the mid left anterior descending artery (LAD) (panel A, upper row). Using the Guardwire Plus system (Medtronic Inc), the wire was positioned in the distal LAD and three aspirations during distal balloon inflation were performed resulting in complete reperfusion (TIMI-III flow) (panel B, upper row) of an angiographically normal appearing LAD (arrow) and normalisation of ST-T segments. The retrieved debris, a large irregular shaped particle (panel A, lower row, arrow), was histopathologically analysed and showed predominantly thrombus (T) with small but non-atherosclerotic parts of vascular media (M) and intima (I) (panel B, lower row, Mason's trichrome). An additional stain for inflammation showed that CD-68 positive macrophages within this part of the

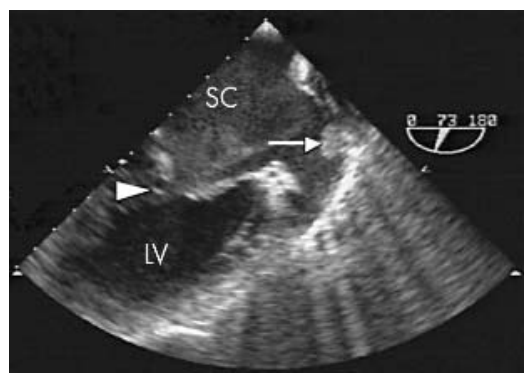

retrieved intima were absent, suggesting absence of atherosclerotic coronary disease. It was hypothesised that the occlusion was due to a significant embolus derived from a prominent thrombus (arrow) found in the left atrial appendage as seen on transoesophageal echocardiography. Also massive spontaneous contrast (SC) was visualised in the left atrium. We suspect that the media and intima found in the
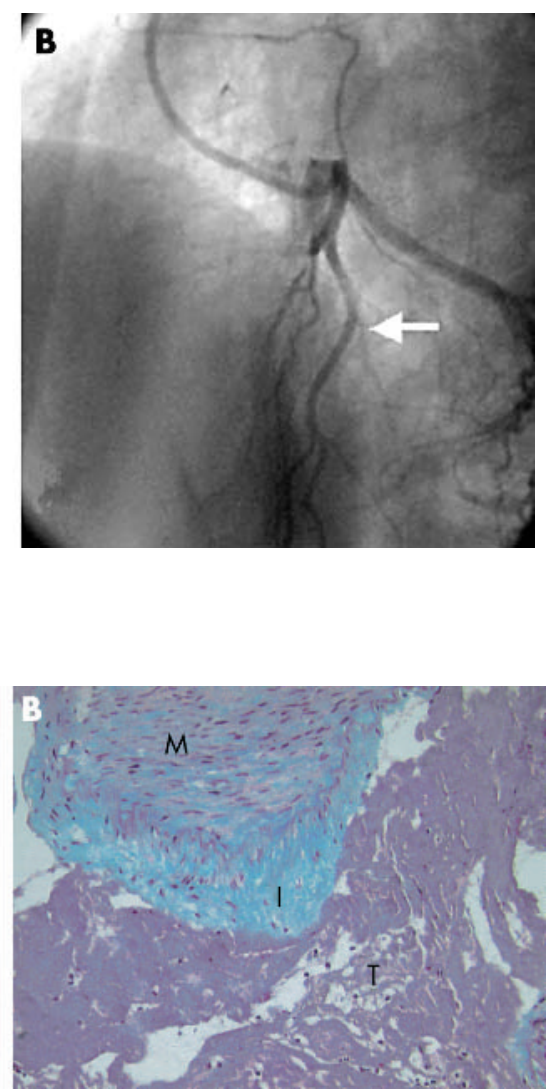

aspirate were most likely obtained following traumatic passage of the aspiration catheter. The patient afterwards underwent mitral valve surgery as well as removal of the intra-atrial thrombus, and recovered well.

J Van der Heyden S Verheye P Vermeersch janenvan@hotmail.com 